\title{
A MEDIAÇÃO CULTURAL COMO CATEGORIA AUTÔNOMA
}

\section{LA MEDIACIÓN CULTURAL COMO UNA CATEGORÍA AUTÓNOMA}

\author{
Edmir Perrotti - perrotti@usp.br \\ Doutor em Ciências da Comunicação pela Escola da Comunicações e \\ Artes (ECA) da Universidade de São Paulo (USP). Docente do \\ departamento de Ciência da Informação da ECA/USP. \\ Ivete Pieruccini - ivetepie@yahoo.com.br \\ Doutora em Ciências da Comunicação pela Escola da Comunicações e \\ Artes (ECA) da Universidade de São Paulo (USP). Docente do \\ departamento de Ciência da Informação da ECA/USP.
}

\section{RESUMO}

Introdução: Reflexão sobre a noção de mediação cultural, como categoria teórica e operacional autônoma, definida em articulação permanente com as da produção e da recepção culturais, considerados processos dinâmicos e complexos que regem a ecologia simbólica.

Objetivo: definir a mediação cultural como instância essencial dos processos de produção de sentido

Metodologia: estudo dos elementos constitutivos de uma experiência cultural autobiográfica, relatada por Clarice Lispector no conto Felicidade Clandestina.

Resultados: a mediação cultural não é simples recurso de transferência de dados/informações, mero "canal" ou instância de apoio visando a criação de elos entre sujeitos.

Conclusão: A mediação cultural é ato autônomo, com identidade e lógicas próprias, definidas em relação com as esferas da produção e da recepção de informação e cultura. Tal abordagem, assumindo modelo triádico (mediação-produção-recepção), rompe com compreensões dualistas e mecânicas dos campos da Informação e da Comunicação, mostrando-se heurística, posto que se compatível com a centralidade dos dispostivos de mediação cultural na atualidade. 
Palavras-chaves: Mediação cultural. Paradigmas culturais. Apropriação cultural.

\section{MEDIAÇÃO CULTURAL: UMA NOÇÃO EM EXPANSÃO}

A noção de mediação cultural vem ganhando interesse crescente nos campos da Informação, da Comunicação e da Cultura, em várias partes do mundo. Em torno dela, são realizadas iniciativas variadas como a criação de cursos universitários e não-universitários de diferentes níveis e durações; a constituição de grupos e linhas de pesquisa em Universidades; o desenvolvimento de associações de profissionais ligadas às áreas culturais; a realização de eventos e publicações, dentre outras ações de igual importância em âmbito científico e social amplo. Tal mobilização merece olhar atento, já que a utilização da noção indica caminhos promissores ao campo da Informação ao qual estamos vinculados.

Dufrêne e Gellereau (2004), Davallon (2004), Jeanneret (2005), Caune (1999a; 1999b) referem-se à "opacidade" que a noção oferece, por remeter a numerosas práticas do campo cultural, sem contar os usos em áreas como a jurídica, a religiosa, a educacional, a das relações internacionais, dentre outras. Tal "opacidade", no entanto, necessita ser enfrentada no terreno científico, considerando-se que para tornar-se operatória, a noção deve ganhar objetividade e precisão, condição para atingir nível teórico, além de reconhecimento científico.

$\mathrm{Na}$ tentativa de fazer um balanço do uso da noção, Duffrêne e Gellereau (2001) propõem o que chamam de "uma primeira tentativa de esclarecimento visando a situar historicamente suas condições de aparecimento e das principais correntes teóricas que Ihes dão sustentação" (DUFFRÊNE; GELLEREAU, 2004, p. 199, tradução nossa). Concluem pela referência a duas metáforas, presentes nas mais diferentes utilizações da noção: a da passagem e a do elo social.

Considerando as colocações feitas pelas autoras, bem como por outros estudiosos (CAUNE, 1999a; CAUNE, 1999b; LAMIZET, 2000; DARRAS, 2003; DAVALLON, 2004; JEANNERET, 2005; La FORTUNE, org., 2012), do ponto de vista histórico, a noção de mediação cultural irradia-se nos quadros de afirmação da cultura da informação (Le DEUFF, 2009) que caracteriza nossa época, a partir, especialmente, do período pós Segunda Guerra Mundial. 
Nesse contexto sócio-histórico e nas sucessivas crises que o acometeram, os aparatos informacionais e comunicacionais passaram a revelar centralidade tão especial na vida cotidiana que levaram autores como Peraya (1999) não só a afirmar a importância deles na contemporaneidade, como a propor uma distinção conceitual entre mediação e mediatização. A onipresença das "tecnologias intelectuais" (GOODY, 2007) na vida cotidiana estaria produzindo, assim, uma espécie de "euforia informacional" que redefine práticas sociais e culturais, colocando em questão concepções clássicas encerradas em relações e termos como público/privado, subjetivo/objetivo, pessoal/impessoal, identidade/alteridade, autonomia/heteronomia, dentre outras.

Assim, se no século XVIII, Laclos nos oferece em Les liaisons dangereuses um magnífico exemplo de manipulação da intimidade, via manipulação da escrita epistolar nas cortes francesas às vésperas da Revolução, na contemporaneidade a questão ganha outros contornos e abrangência, envolvendo não só o círculo restrito de cortesãos em crise, mas a todos nós. Talvez, como à época, a ideia de apropriação indébita de informações continue fazendo sentido, como testemunham os acalorados debates que vivenciamos sobre direitos autorais e sobre o direito de publicação de biografias. Todavia, não só a natureza dos objetos informacionais vem se alterando, como também os motivos do "roubo", a posição do "ladrão" e do "proprietário", dentre outros aspectos fundamentais implicados no problema. Um caso não muito distante ainda, envolvendo o "roubo" de imagens íntimas de uma atriz da Rede Globo, é exemplar. Conforme veiculado, as imagens foram produzidas para circular exclusivamente entre ela e seu namorado. No entanto, vazaram na $W E B$, levando o casal a registrar queixa à polícia. A questão que fica é se esta conseguirá protegê-los ou se a atriz global estará fadada a interpretar, em versão contemporânea e digital, o papel de Mme. Verteuil, situação no mínimo paradoxal, que embaralha limites estabelecidos entre representação e realidade.

Se a mediação é categoria intrínseca a qualquer processo cultural, nem sempre sua importância foi destacada e compreendida em sua essencialidade. Nas hermenêuticas de bases idealistas, assim como nas funcionalistas, tendeu, por exemplo, a ser vista como elemento espúrio, tolerado apenas, posto que inevitável. Foi reduzida, em decorrência, a "apoio", "instrumento", colocada num papel meramente funcional, instrumental, nos processos de significação. A condenação da escrita por Platão, em Fedro (2002), não obedece a outra lógica e é coerente com 
seu modo de interpretação do mundo que opera a partir de oposições binárias como aparência/essência, falso/verdadeiro, instrumental/essencial. Segundo ele, não poderia ser deixado a um instrumento- a língua escrita- um lugar tão especial na vida da polis, já que isso ameaçaria a possibilidade de os cidadãos chegarem à essência, situada além das aparências.

No quadro histórico e cultural em que nos encontramos, novas leituras dos fenômenos informacionais e comunicacionais são propostas, conferindo centralidade aos processos de mediação cultural. O conceito de zona de desenvolvimento proximal, de Vigotsky (1991), de bases sociointeracionaistas, será talvez a melhor expressão das compreensões que emergem em várias áreas do conhecimento, dentre elas a dos estudos culturais. Segundo estas, tal como as categorias da produção e da recepção, a da mediação, além de intrínseca e essencial, é categoria produtora e não apenas viabilizadora de sentidos. Pode-se dizer, assim, que não há informação ou comunicação sem mediação. $E$ que, nos tempos atuais, as mediações, ao serem mediatizadas, mediatizaram as relações sociais, ganhando estatuto que obriga a colocá-las em posição de centralidade epistemológica. Afinal, num ponto a história não desmentiu Platão: a economia simbólica e a economia política atuam de modo articulado. Como interpretar e regular isso, eis debate aberto, que depende de tomada de posições históricas e de avanços epistemológicos.

\section{UMA CATEGORIA SITUACIONAL}

O termo mediação cultural, como foi acima mencionado, é utilizado em diferentes contextos, recobrindo um conjunto multiforme de práticas culturais. Em decorrência, Davallon (2004), assim como outros autores aqui citados, alertam para a necessidade de tratá-la como noção situacional, ou seja, categoria pensada em relação a contextos e processos precisos, já que se pode falar tanto em mediação cultural em contextos difusos, como em museus, bibliotecas, teatros e outros equipamentos culturais, considerando-se, ainda, em relação a estes uma gama diversificada de manifestações diferenciadas em cada um desses equipamentos. Nas bibliotecas, por exemplo, temos ações de mediação envolvendo processos diferenciados como a constituição de acervos, sua gestão e disponibilização ao 
público, dentre outras de igual relevância e que se encontram no mesmo campo de ações.

Todavia, em que pesem dificuldades como a "opacidade" referida, decorrentes das características específicas de cada contexto e de cada prática, tal fato não desqualifica a tentativa de alçar a noção à categoria teórica, segundo estudiosos que a ela vêm se dedicando, consideradas suas possibilidades heurísticas. Como sublinha Davallon (2004), ampliando o debate a respeito, talvez não esteja em causa simplesmente a pertinência teórica da noção. É possível que esteja em processo, a partir e com ela, uma ruptura de quadros epistemológicos que validaram concepções limitantes de informação e comunicação, reduzindo a mediação cultural à categoria meramente funcional ou instrumental que consiste em "fazer aceder um público a obras (ou saberes)" ou "em construir uma interface entre esses dois universos estranhos um ao outro". Ganha relevância, desse modo, o esforço de compreensão dos sentidos encerrados na noção de mediação cultural como ato de significação (BRUNER, 1997), já que isso poderá representar um salto epistemológico fundamental, contribuindo tanto para a redefinição da noção, como para compreensões mais gerais acerca dos campos da Informação, da Comunicação e da Cultura.

Com tais propósitos, será examinada a seguir uma situação narrada por Clarice Lispector, no conto Felicidade Clandestina (1981), envolvendo aspectos que permitem refletir sobre a noção de mediação cultural e desdobramentos epistemológicos que lhe são correlatos, quando tomada em dimensão autônoma.

\section{DA MEDIAÇÃO EM SITUAÇÃO: FELICIDADE CLANDESTINA}

Em Felicidade Clandestina, Clarice Lispector narra uma situação vivida por ela na infância, no Recife. Uma de suas colegas, filha do dono de uma livraria, no meio de uma conversa, de modo calculadamente casual, diz possuir As Reinações de Narizinho, de Monteiro Lobato. Sabia que Clarice ficaria tocada pela informação, coisa que efetivamente ocorre: "Era um livro grosso, meu Deus, era um livro para se ficar vivendo com ele, comendo-o, dormindo-o. E completamente acima de minhas posses. Disse-me que eu passasse pela sua casa no dia seguinte e ela o emprestaria". 
Tem início, assim, um jogo que se mostrará cruel e que durará vários dias, pois a "filha do dono da livraria" tinha um plano "diabólico": prometer o livro ardentemente desejado e, ao mesmo tempo, ir inventando as mais descabidas desculpas para não emprestá-lo. Assim, no dia seguinte, conforme combinado, Clarice vai à casa da colega pegar o livro, mas esta diz que o tinha emprestado a outra menina. Que ela voltasse no dia seguinte! Ela volta, mas como ocorrerá repetidas vezes, novamente o livro não podia ser emprestado, pois não estava em poder da dona. Clarice, na condição de narradora adulta, então desabafa: "Na minha ânsia de ler, eu nem notava as humilhações a que ela me submetia: continuava a implorar-lhe emprestados os livros que ela não lia".

Após muitas recusas e frustrações, um dia aparece a mãe da menina, na porta da casa, e o rumo dos acontecimentos muda, quando ela toma conhecimento do que acontecia: "mas, este livro nunca saiu daqui de casa e você nem quis ler!", diz para a filha. E completa: "você vai emprestar o livro agora mesmo". E, virando-se para Clarice: "E você fica com o livro por quanto tempo quiser."

Quase sem acreditar, a menina volta para casa abraçada ao livro e, a partir daí, vive momentos de intensa magia e poesia: "Chegando em casa, não comecei a ler. Fingia que não o tinha, só para depois ter o susto de o ter. Horas depois, abri-o, li algumas linhas maravilhosas, fechei-o de novo, fui passear pela casa, adiei ainda mais indo comer pão com manteiga, fingi que não sabia onde guardara o livro, achava-o, abria-o por alguns instantes. Criava as mais falsas dificuldades para aquela coisa clandestina que era a felicidade. A felicidade sempre iria ser cladestina para mim. Parece que eu já pressentia. Como demorei! Eu vivia no ar...Havia orgulho e pudor em mim. Eu era uma rainha delicada."

Por fim, a menina refere-se ao efeito produzido nela pelas "Reinações de Narizinho": "às vezes, eu sentava na rede, balançando-me com o livro aberto no colo, sem tocá-lo, em êxtase puríssimo. Não era mais uma menina com um livro: era uma mulher com seu amante."

\section{O EMBATE CULTURAL}

A primeira observação que pode ser feita, em relação à questão de nosso interesse, é que o conto organiza-se em torno de um conflito, envolvendo um objeto cultural -o livro Reinações de Narizinho -, além de duas meninas e a mãe de uma 
delas. Em posições contrárias, situam-se, de um lado, a menina Clarice, movida por seu desejo de ler; de outro, a menina dona do livro, movida por seu "plano diabólico" de impedir a realização do desejo da outra. Desse modo, foi preciso que a mãe desta interviesse para solucionar o embate que, de outra forma, dificilmente se resolveria.

Temos aí, portanto, uma relação conflituosa, em torno de um objeto cultural e uma resolução, graças à mediação de um terceiro elemento externo, mas autorizado para tanto, por sua condição de adulta, como de mãe da menina possuidora do livro. Trata-se, desse modo, de luta ancorada, de um lado, na posse do objeto material; de outro, na posse de chaves cognitivas que permitem a Clarice, mesmo sem a posse jurídica do objeto físico, a fruição de dimensões simbólicas que a transcendem, mas que dependem do acesso ao objeto. Sabedora de tal exigência colocada pelo objeto cultural em causa, a "filha do dono da livraria" encontra, então, terreno fértil para exercer, com "calma ferocidade", o seu sadismo até que a "boa mãe" tome conhecimento dos fatos e coloque limites ao narcisismo da filha.

A experiência cultural aparece no conto, portanto, como embate em torno de questões simbólicas, profundamente imbricadas aos vários aspectos que constituem a vida social e cotidiana. A leitura, como se vê ali, não é fenômeno etéreo, à margem de lutas, disputas, paixões, interesses, emoções, sentimentos que caracterizam o viver junto. Ainda que gozando de estatuto singular, capaz de produzir transfigurações como a indicada no final do conto ("não era uma menina com um livro: era uma mulher com seu amante"), a atividade simbólica está conectada a questões econômicas, políticas, sociais, comportamentais concretas e decisivas; é, ao mesmo tempo, como a define Escarpit (1974) "ato" e "gesto", fenômeno que envolve tanto aspectos singulares, únicos e inarredáveis dos sujeitos, como aspectos plurais e comuns do "mundo".

Nesse jogo entre aspirações e desejos próprios a cada um e dinâmicas e realidades dos contextos socioculturais, apresenta-se como fundamental, pois, a existência de uma zona de conexão, um território "entre", onde forças dinâmicas de variadas naturezas se encontram e negociam os destinos dos signos. No caso específico do conto, vale notar que a situação ocorre à porta da casa da menina possuidora do livro, ou seja, num espaço de transição entre o privado e o público, o particular e o geral, a casa e a polis. Nesse espaço transicional (WINNICOTT, 1975), atua, portanto, a mãe, como força mediadora legítima e fundamental, que, ao 
perceber o conflito, entra em cena, demonstrando a importância das instâncias reguladoras externas, quando, por alguma razão, falham mecanismos internos e internalizados pelos sujeitos, como condição indispensável à vinculação com o outro. Segundo Betthelheim (1980), o percurso do herói nos contos de fadas consiste exatamente nesse processo de conquista da alteridade, dessa zona intersubjetiva que permite $\circ$ trânsito entre $\circ$ mundo revolto dos afetos e as leis impostas pelo mundo comum. De acordo com suas referências, o vilão seria aquele que se perde nas amarras narcísicas, tal como está ocorrendo com a menina, dona do livro. Este já não é um objeto comunicacional e artístico para ela. É arma destinada a golpear a outra, por ser esta capaz de navegar em territórios a ela inalcançáveis, mesmo detendo a posse jurídica do objeto. Daí a importância assumida pela mãe: de um lado, permite a realização do desejo de Clarice; de outro, põe limites aos desejos perversos da filha, mostrando-lhe caminho necessário à constituição desse território de interconexão que the falta e que a impede de se relacionar, de pertencer, de penetrar nos domínios simbólicos propostos pelo livro: "Mas esse livro nunca saiu aqui de casa e você nunca quis ler".

Os objetos culturais são signos e, mais que isso, discursos potencialmente capazes de produzir deslocamentos intelectuais, emocionais, afetivos, como ocorreu com a informação dada a Clarice sobre o livro de Monteiro Lobato. Por outro lado, constituem-se como realidades concretas e objetivas, permeadas e dividindo o espaço social com outros fenômenos e sujeitos. Daí demandar tanto a posse material, como chaves subjetivas que são de ordem distinta, embora inclua a dimensão material e sensível. Outra menina, sem a experiência anterior de Clarice com a leitura, poderia ter reagido de maneira diferente diante das informações recebidas. Suas memórias, porém, criam condições de resistência e a projetam em direção a um futuro, mesmo tendo que se submeter aos desígnios da dona do livro.

A esperança da experiência leitora é força motriz restauradora. Nesse sentido, é preciso atentar para o fato de que a noção de mediação cultural é formada por dois termos, um substantivo e um adjetivo. O primeiro, em comum com os diferentes campos em que é utilizado, refere-se ao ato de intermediar relações. Jeanneret (2005, p.106, tradução nossa) lembra que o termo tem origem nos campos religioso ("os anjos e os padres são mediadores entre Deus e os fiéis") e jurídico ("a mediação é uma tentativa de conciliação em um processo"), referindo-se, portanto, à "necessidade de intermediários e de terceiros, (face a) uma consciência 
da complexidade de certos fenômenos, mais que de um conteúdo definido". Temos aí, portanto, um termo (mediação) que remete ao campo das relações, das intermediações sociais entre sujeitos.

De outro lado, temos o adjetivo "cultural" que o qualifica, restringe, particulariza, circunscrevendo-o ao domínio semiológico, distinguindo a "mediação cultural" de outras formas de mediação (política, econômica, social, religiosa, diplomática), com as quais mantém afinidades, mas ao mesmo tempo se diferencia. Em outras palavras, tal como nos demais campos, a mediação cultural é um ato de intermediação por um "terceiro" visando viabilizar relações e convivência dos sujeitos entre si- o "viver junto", ao qual se refere Caune (1999a).

Em outra perspectiva e ao mesmo tempo, é ato envolvendo uma classe específica de objetos e processos que encerram uma dimensão simbólicasemiológica especial e autônoma, mesmo se em interação dinâmica com os fluxos que caracterizam as lógicas do mundo concreto. Trata-se de uma noção complexa, nos termos propostos por Morin (2005). Nesse sentido, se a mediação apresenta-se como "terceiro" (DAVALLON, 2004), cujo desempenho é indispensável às trocas impostas pelas condições do "viver junto" (CAUNE, 1999a), ela não é apenas "ação de servir de intermediário (...) entre dois seres" (LALANDE, 1993, p.656), "metáfora da passagem" e dos "elos sociais" (DUFRÊNE; GELLEREAU, 2001). Além desses aspectos funcionais e instrumentais, ela é ação portadora de sentidos próprios que estão em relação com sentidos incrustados tanto nos objetos, como nos sujeitos culturais e seus respectivos contextos.

Ao analisar o uso da noção de mediação cultural no campo da Informação e da Comunicação, Davallon (2004) considera as metáforas da "passagem" e dos "elos sociais" procedentes. Todavia, filia-as ao "senso comum", pois, segundo ele, a verificação mais apurada das dinâmicas culturais mostra que "a noção de mediação aparece cada vez que há necessidade de descrever uma ação implicando uma transformação de situação ou do dispositivo comunicacional, e não uma simples interação de um elemento de um polo para outro" (p. 10, tradução nossa). Em função disso, avança uma hipótese: "há recurso à mediação quando há falha ou inadaptação das concepções habituais da comunicação: a comunicação como transferência de informação e a comunicação como interação entre dois sujeitos sociais." (p. 10, tradução nossa). Tal formulação traz consequências práticas e teóricas por ele explicitadas: "a origem das ações desloca-se do atuante destinador 
ou dos inter-atuantes para um atuante terceiro: há comunicação pela operação do terceiro." (p. 10, tradução nossa). A mediação, em tais circunstâncias, além da dimensão funcional, é força ativa e instituinte, é, ela própria, ato de criação.

No conto de Clarice, verificamos que o aparecimento da mãe (o "terceiro") altera o rumo dos acontecimentos. Sua ação é definidora na reversão do quadro dado. "E você, fique com o livro o tempo que quiser (...). Valia mais do que me dar o livro: 'pelo tempo que eu quisesse' é tudo o que uma pessoa, grande ou pequena, pode ter a ousadia de querer... Como contar o que se seguiu? Eu estava estonteada, e assim recebi o livro na mão." A ação desempenhada pela mãe, no conto, tomando-se colocações de Caune (1999a) restaura e reafirma valores "transcendentes" e partilhados que fundam o "viver comum". Nesse sentido, a mediação cultural não se constitui meramente como jogo de saberes especiais ou especializados em vista de um fim determinado que the é exterior. É ato de afirmação ética, destinado a transcender o âmbito dos interesses mundanos. Segundo ele, a mediação apresentaria dupla direção. De um lado, estaria um "eixo horizontal, o das relações interpessoais"; de outro, um "eixo vertical, o de um sentido transcendental que orienta as relações longas". Decorre daí que "a mediação como projeto social não pode se contentar com o estabelecimento de laços efêmeros, ela deve também participar na produção de um sentido que envolve a coletividade" (CAUNE, 1999a , p.2). Em outras palavras, a mediação não é somente um ato "funcional" ou de âmbito restrito; é também discurso, ato de produção de sentidos que se realiza no campo amplo e dinâmico da cultura.

Ora, a ação da mãe corresponde, sem dúvida, a um imperativo público: o do "viver juntos". Seu ato restaura princípios de convivência que estavam sendo negados pela atitude da filha. Nesse sentido, se o "terceiro" corresponde a um locus, mais que espacial, este locus é também político, ético, semiológico -posto que fundado em linguagens partilhadas-, tomando como critério orientador necessariamente relações de poder e valores que dizem respeito à vida comum. $\mathrm{A}$ mediação cultural, afirma Caune, "passa antes pela relação do sujeito com o outro, por meio de uma 'palavra' que o engaja, porque ela se torna sensível em um mundo de referências compartilhadas. O sentido não é então concebido como um enunciado programático, elaborado fora da experiência comum, mas como o resultado da relação intersubjetiva, isto é, de uma relação que se manifesta na confrontação e na troca entre as subjetividades" (1999a, p. 1, tradução nossa). 
Se a mediação é categoria fundante em qualquer organização social, de tal modo que no campo filosófico caracteriza as relações entre o sujeito e o mundo, em nosso tempo as interrogações sobre ela retornam, face à tripla crise do trabalho, da representação política e da arte, três domínios constitutivos da condição do homem moderno, segundo Hannah Arendt (1983). Diante de tal crise, como pode o indivíduo "encontrar as vias e as expressões de seu desenvolvimento, de sua relação com o outro, de sua inscrição em uma comunidade", pergunta Caune, no artigo citado (p. 2, tradução nossa). Sua resposta aponta para a crítica e superação da definição instrumental de mediação e a necessidade de precisá-la: "o uso indiferenciado da noção de mediação vale como sintoma de uma sociedade que teme reconhecer os conflitos, busca os espaços do diálogo e do consenso e, enfim, aspira renovar o tecido social rompido pelo desenvolvimento incontrolado da lógica mercantil" (CAUNE, 1999a, p.3, tradução nossa).

Considerados tais termos, a mediação cultural aparece como categoria que se referenda na esfera pública, nos sistemas axiológicos que fundam "a natureza do tecido social". Dada a irressimissilidade dos conflitos, não se trata tão somente de fazer a transmissão ou permitir o acesso aos signos. É preciso criar vínculos simbólicos entre os diferentes, espaços de transição, pontos de convivência que tornam possível o "viver juntos", em especial em época de mudanças que alteram relações de tempo e espaço, via tecnologias virtuais cada vez mais onipresentes na experiência cotidiana, em escala global.

\section{O IMPERATIVO ONTOLÓGICO}

No conto de Clarice, a mãe ordena que a filha empreste o livro pelo tempo que a outra quisesse, quase um não-tempo. "É tudo o que uma pessoa grande ou pequena pode querer", diz Clarice. Ora, se a propriedade jurídica do livro continua sendo da filha, quem irá se apropriar de seus conteúdos, de sua dimensão simbólica, é a outra. Atuando no corte existente entre o mundo material e o imaterial, a mãe consegue atender, assim, tanto exigências do regime legal que reconhece o direito à posse do objeto pela menina que não lê, quanto às do regime simbólico que reivindica o livro para ser vivido como experiência sígnica que extrapola a posse jurídica do objeto. Consegue, portanto, acatar dois imperativos que ordenam o contexto social, instituindo um equilíbrio que, sem sua intervenção, dificilmente seria 
obtido. Interesses gerais e particulares foram compatibilizados, viabilizando o "estar juntos", ainda que a tensão inicial permaneça presente na situação, confirmada anos mais tarde, quando será retomada pela menina já adulta e investida do novo papel de narradora/mediadora. Na nova condição, a situação se inverte. Clarice possui a arma simbólica da palavra escrita e, numa espécie de ajuste de contas, expõe o caso ao leitor, reabre-o em outra dimensão, transformando o embate privado em questão pública, ao transformá-lo em narrativa. Comprometido com a cultura, o narrador funciona como um mediador em segunda instância, que, como a mãe, busca superar os particularismos como critério de organização social e cultural.

O conto nesse aspecto confere aos atos de mediação uma dimensão ontológica que extrapola tempo e espaços históricos, remetendo a questões que dizem respeito à sobrevivência da espécie. Mais do que mãe da menina, mais do que narradora que se compraz em lastimar as dores do mundo, as mediadoras assumem uma dimensão arquetípica regeneradora, comprometida com a continuidade da vida. Trava-se, assim, uma luta ética e épica entre o bem e o mal, ainda que historicamente situada e concretizada em situação corriqueira, aparentemente banal. A mediação cultural, em tais condições, assume uma dimensão reguladora superior, ocupando-se tanto de desvios narcisísticos primários, como de eventuais desmandos realizados em nome da ordem pública.

\section{AÇÃO DEONTOLÓGICA}

O aparecimento da mãe e os desdobramentos daí decorrentes mostram uma dimensão fundamental da mediação. O modo como esta se dá pode contribuir tanto para a obstrução, como para a desobstrução de dificuldades que a experiência sociocultural sempre coloca, seja por razões prioritariamente histórico-sociais objetivas, seja por outras de natureza mais especificamente cognitivas ou subjetivas ou, ainda, pela mesclagem de ambas envolvendo relações dos sujeitos com os signos em situações concretas precisas.

No caso específico, a menina Clarice consegue ter acesso ao livro e viver seus momentos especiais de "felicidade clandestina". Tais vivências, todavia, tornaram-se possíveis pela ação da mãe. Com isso, fica claro que a mediação, ao viabilizar nossas relações com o mundo, ao se objetivar em signos, atos, gestos e objetos sensíveis, define contornos e direções, modos de relação com os objetos, os 
signos e o outro. Por isso, Darras (2003) afirma existirem diferenças essenciais entre o difusor e o mediador. O horizonte de expectativas do primeiro é a assimilação das mensagens pelo "receptor", tomado como categoria isolada e particular. $\mathrm{O}$ do segundo, é a cultura, ou seja, a esfera pública da criação de sentidos. Nessa perspectiva, a mediação não é apenas operação: é ação deontológica sobre a cultura e o mundo, modo especial de produção legitimada por imperativo éticoontológico que ultrapassa e se distingue do imperativo da funcionalidade que sustenta o tecnicismo. Segundo este, o critério regulador de todas as coisas é a eficácia dos processos de transferência de estímulos. As significações, os sentidos Ihes são alheios. A mediação cultural nessas condições pode se reduzir a mero conjunto de procedimentos, estratégia.

\section{MEDIAÇÃO, RECEPÇÃO E PRODUÇÃO: O MODELO TRIÁDICO E SEMIÓTICO}

A tenacidade da menina Clarice chama a atenção no conto. Não fosse isso, talvez não houvesse possibilidade de intervenção da mediadora. É "a aparição muda e diária daquela menina à porta de sua casa" que lhe permite atuar, modificando o rumo dos acontecimentos. Nesse sentido, o conto estabelece uma conexão entre os contextos da mediação, da recepção e da produção cultural, apontando para um modelo sistêmico e especular, em que cada categoria, em sua irredutibilidade, reflete e refrata a outra, num processo dinâmico e complexo de interferências múltiplas. Não é gratuitamente que a menina se submete aos desígnios perversos da filha do dono da livraria. Ela não deseja somente um livro; ela deseja Reinações de Narizinho, de Monteiro Lobato. Clarice já era leitora, tinha estabelecido uma relação significativa com os códigos e a cultura escrita, conhecia Lobato, segundo o que se pode inferir da leitura do conto. Assim, sabia das promessas contidas naquele livro especial. Por isso, não só lutou por ele, como, ao consegui-lo, passou a brincar com ele, bem como com o tempo e o espaço da leitura: "Chegando em casa, não comecei a ler. Fingia que não o tinha, só para depois ter o susto de o ter." E, continua, "Horas depois abri-o, li algumas linhas maravilhosas, fechei-o de novo, fui passear pela casa, adiei ainda mais indo comer pão com manteiga, fingi que não sabia onde guardara o livro, achava-o, abria-o por alguns instantes."

Desse modo, fica evidente o papel afirmativo e essencial atribuído no conto às esferas da recepção e da produção cultural, em conexão com a da mediação. 
Articuladas, as três configuram, como diz Davallon (2004, p.23, tradução nossa), "uma nova maneira de conceber a comunicação", que faz aparecer "menos os elementos (a informação, os sujeitos sociais, a relação, etc) do que a articulação desses elementos num dispositivo singular (o texto, o média, a cultura). É, no fundo, esta articulação que aparece como o "terceiro" -apontado por vários autores, dentre os quais Martin-Barbero (1991)- como categoria essencial, capaz de dar conta, ao mesmo tempo, de aspectos relacionais e semiológicos próprios dos atos culturais. Segundo tais perspectivas, podemos dizer que, no conto, saímos de um modelo de informação e de comunicação definidos de modo diádico, passando a um modelo triádico, como segue:

Figura 1 - Modelo tríadico

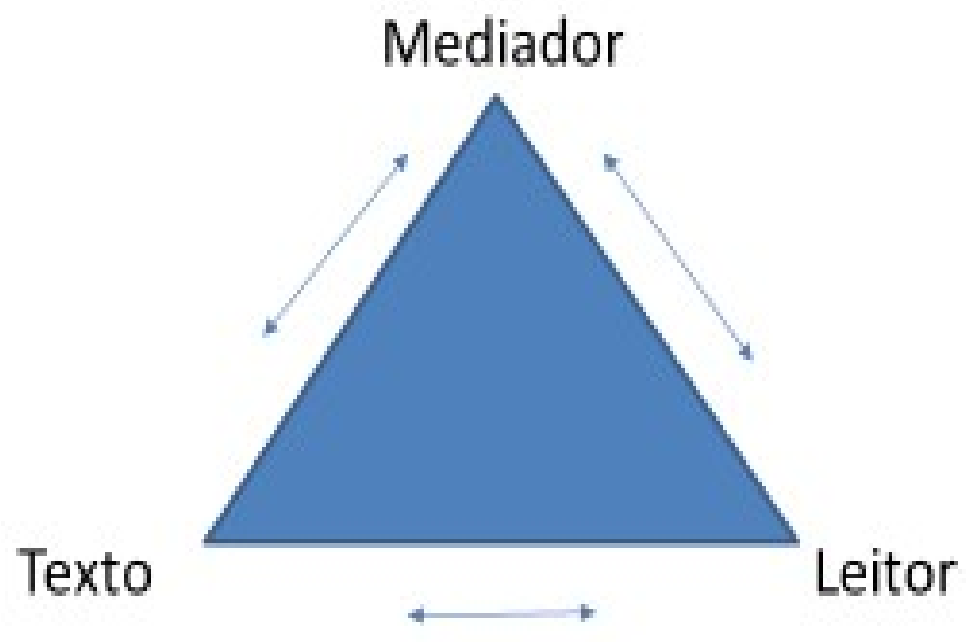

Fonte: produzido pelos autores

É preciso salientar que tal ruptura paradigmática vem ancorada em uma nova lógica que rompe hermenêuticas idealistas, mecanicistas e positivistas, não só por incluir um "terceiro", mas por incluí-lo como categoria de significação, ausente ou tratada como "pré-científica" nos modelos de origem matemática. Estes, como observa Jeanneret, nascidos "de um modelo técnico (o da transmissão)" conduzem 
"a uma ideia forte" de associação "função- mediação", criticada "como uma ilusão interessada pelos sociólogos da cultura e das instituições", como Bourdieu. Para este, a mediação não se reduziria a uma transmissão voluntária de ideias, mas a um "processo de interiorização de normas e comportamentos que nos conduzem a adotar certas práticas como se elas fossem naturais", ou seja, o que Bourdieu (1980) chamaria de "habitus". (JEANNERET, 2005, p. 106, tradução nossa). Tal atitude, segundo Jeanneret tem um desdobramento importante, em relação à compreensão do termo: "o fato de se interessar por todas as práticas que fazem circular efetivamente as ideias e os saberes na sociedade, permitiu uma melhor compreensão da riqueza e da dimensão criativa do trabalho dos mediadores (entendidos aqui menos como intermediários que como atores da transformação cultural), vulgarizadores, bibliotecários, editores, jornalistas, professores, militantes, experts, etc" (2005, p. 106, tradução nossa). Estes mobilizam um conjunto muito diverso de mediações, e tal como já haviam salientado Dufrêne e Gellereau (2001), necessitam ser pensados como um "sistema de mediações" que atua nos processos de construção de sentidos.

Darras (2004) observa que "desde a primeira etapa de toda produção de signo, mediação e cultura estão associadas nos processos interpretativos" (p.73, tradução nossa). Se nos referirmos à estrutura do signo, tal como ela é definida por C.S. Peirce, estas categorias constituem um dos três componentes necessários do signo, o "terceiro". Nesses termos, "o interpretante funciona como uma representação mediadora, um intérprete, um terceiro, que emerge de um conhecimento já estabelecido, remetendo mais largamente ao conjunto de representações e crenças que constitui a cultura." (p. 73, tradução nossa). Dessa referência, Darras tira uma conclusão importante: "se o processo de mediação por entidades culturais está presente em todas as operações semióticas, a mediação da cultura é um fenômeno elementar do pensamento e os "intérpretes", aos quais Peirce faz referência, são ativos em cada operação semiótica". Daí que "a mediação é, portanto, um processo de acompanhamento semiótico necessário que intervém em cada ocasião de fabricação dos signos" (p. 73, tradução nossa). 


\section{MEDIAÇÃO E DISPOSITIVOS}

A situação narrada por Clarice transcorre em um espaço doméstico, onde a figura da mãe exerce papel regulador fundamental, como parte de suas funções familiares implícitas. Darras (2004) chama a atenção, entretanto, para o fato de que o "sistema de mediações" contemporâneo implica cada vez mais formas de "mediação profissionais" que não são difusas, exercidas apenas como função residual nas práticas sociais. Ao contrário, crescem em nosso tempo os dispositivos de mediação cultural que são organizações especializadas, pautadas por lógicas e intencionalidades próprias.

Tal distinção entre a "mediação difusa" e a "profissional" é fundamental, já que, como vimos, a instância da mediação, no conto, atuou como elemento que desobstruiu o acesso ao livro, amparando-se em valores éticos abrangentes e não pela lógica da manutenção dos laços familiares, acima de qualquer outra razão. A mãe de família assumiu sua porção cidadã de mediadora que possibilitou a experiência cultural de uma criança desconhecida, mas desejosa de ler, sem abrir mão, contudo, da porção educadora que, por sua atitude, oferece elementos para inserir a filha em ordem de discurso e de experiência vinculantes. A continuar procedendo como vinha fazendo, a filha estará condenada ao isolamento, ao não pertencimento, presa a forças narcísicas que a impedem de crescer e de relacionarse. A ação equilabradora é, pois, em duplo sentido. Como lembra Jeanneret (2005), a sociedade não é "uma simples coleção de indivíduos", ou seja, de funções, mas um "conjunto de valores, de práticas compartilhadas, de lugares de memória que de um certo modo transcende o cotidiano das trocas" (p. 106, tradução nossa). Mediar é, nesse sentido, vincular ao mundo, é ação de construção de identidades culturais. Por isso, Caune (1999b), ao examinar abordagens da noção de mediação, conclui com a pergunta: "pode (o setor cultural) limitar-se à difusão e à recepção das formas artísticas legitimadas pelo 'mundo da arte'? Não deve incluir nesse domínio as práticas sensíveis ou inteligíveis que permitem à pessoa se construir em sua relação com o outro"? (p. 2, tradução nossa).

As questões da especialização e da profissionalização da mediação cultural são, pois, aspectos que necessitam ser considerados na reflexão sobre o tema, já que as lógicas que a informam no presente diferem da lógica que orientou as decisões da mãe, no conto de Clarice. O "sistema de mediações" de nossa época, 
marcado por descontinuidades, impessoalidades, conflitos de interesses de toda ordem, sobreposição de referências culturais díspares, presença crescente de organizações especializadas, de tecnologias de informação e comunicação que permitem o estabelecimento de relações mediadas por máquinas com alcance global, que comunicam a distância em "tempo real", não apresenta o mesmo estatuto dos sistemas de mediações tradicionais em que o conceito de comunidade tinha ainda algum sentido, como ocorre no conto. O "fio da tradição" (ARENDT, 1978) rompeu-se, o "fim das certezas" (PRIGOGINE, 1996) tomou conta do campo histórico e cultural em tempos de globalização e de mediatização. Em consequência, os dispositivos de mediação cultural mudaram de caráter e, mais do que em outras épocas, motivados pela forte concorrência existente no mercado dos signos, transformam-se em territórios premidos permanentemente por necessidades de auto preservação, nem sempre compatíveis com as exigências "transcendentais" a que se refere Caune (1999a) e que caracterizou a ação materna, em questão.

Atento às dificuldades próprias da nova condição dos processos de mediação cultural, Jeanneret (2005) chama atenção para uma de suas contradições: o crescimento dos dispositivos institucionais e tecnológicos próprios da contemporaneidade "poderia indicar uma necessidade de intermediários e de terceiros, uma consciência da complexidade de certos fenômenos" (p. 105, tradução nossa). Todavia, "essas transformações parecem invisíveis porque a 'rede' é apresentada sistematicamente como um desaparecimento dos intermediários- o que ela não é, de modo nenhum" (p. 107, tradução nossa). Daí, segundo Jeanneret (2005) "uma das grandes questões políticas colocadas pelos dispositivos ligados à 'sociedade da informação', é saber se esses standards regulamentarão sozinhos a questão dos intermediários e a do terceiro, ou se o conjunto dessas transformações poderá ser discutido" (p. 107, tradução nossa). Em outras palavras, estão colocadas aí preocupações com o destino dos processos de mediação cultural na contemporaneidade, visto que, tanto para o senso comum, como para a "ilusão interessada", "a sociedade da informação seria uma sociedade sem mediação" (...) uma sociedade que colocaria em contato, diretamente, graças a aparelhos mais ou menos mágicos, espírito com espírito, seres com seres, liberdade com liberdade, desejo com desejo" (p. 107, tradução nossa). 


\section{CONSIDERAÇÕES FINAIS: UMA REDEFINIÇÃO DE PARADIGMAS CULTURAIS}

Em trabalho anterior (PERROTTI; PIERUCCINI, 2008), referimo-nos a relações historicamente estabelecidas entre paradigmas culturais e dispositivos de informação e cultura, citando exemplo das bibliotecas, objeto de pesquisas por nós levadas a efeito, tendo em vista a criação de referências capazes de contribuir para a renovação de tais dispositivos. Assim, destacamos três paradigmas: o da "conservação", da "difusão" e da "apropriação cultural", paradigma este que está diretamente relacionado à noção de mediação, tomada como objeto autônomo, ato afirmativo de significação, como tratado.

Se até os Tempos Modernos, as bibliotecas foram concebidas exclusivamente como "templos do conhecimento", acessíveis somente a iniciados, essa concepção, com a modernidade, teve que ir se renovando, pois nova palavra de ordem emergia com a hegemonia da ordem social burguesa: o acesso à cultura. Mote cultivado pela llustração, tal ideario foi aos poucos se propagando em várias partes do mundo. As bibliotecas, mesmo se lentamente, tiveram que se refazer enquanto instâncias de difusão cultural.

Entre essa intenção difusionista declarada e a realização efetiva do projeto houve, contudo, um hiato enorme, motivado por diferentes razões (políticas, técnicas, econômicas, sociais e culturais). Em países como o Brasil, o hiato ampliouse, dadas dificuldades para acomodar as novas palavras de ordem ao passado colonial e aristocrático. A concretização das propostas de "cultura para todos", a "universalização do elitismo" (DARRAS, 2004) não só andaram e andam a passos extremamente lentos, como revelaram-se inoperantes, por desconsiderarem os vínculos inexoráveis existentes entre as esferas material e simbólicas nos processos culturais. Por exemplo, muitos dos objetos tidos como de excelência cultural pelas elites dificilmente conseguem corresponder aos interesses das massas que se encontram excluídas de dimensões da vida política e social que lhes deram origem e sentido; por outro lado, mesmo em situações em que a oferta cultural foi promovida, foram sonegados saberes e experiências indispensáveis à apropriação dos signos. As políticas de oferta satisfizeram-se com a disponibilização da produção cultural, sem se preocuparem com as mediações e os contextos culturais da recepção. Aplicaram à cultura os mesmos princípios que regem a dinâmica das mercadorias, 
esgotando-se num distributivismo cultural muitas vezes inócuo e que, dadas situações contemporâneas, dificilmente ultrapassa o nível do consumismo.

Tal situação levou autores como Darras (2004) a distinguir "democratização cultural" de "democracia cultural", noção esta que se articula com o que denominamos "paradigma da apropriação cultural". Segundo este, os dispositivos culturais passam a ser concebidos como instâncias de negociação de signos por sujeitos tomados em sua dimensão de criadores culturais, da mesma forma que os processos de mediação passam a ser entendidos como ato constitutivo dos processos de construção de sentidos e, ele próprio, instância produtora de significação. Mediar cultura, nesses termos, é, portanto, atuar na elaboração de espaços transicionais (WINNICOTT, 1975) indispensáveis à construção de si em relação com o outro.

Mediar é ato autônomo e afirmativo de criação. Do mundo e de sentidos para ele.

\section{REFERÊNCIAS}

ARENDT, H. A crise da cultura. In : . Entre o passado e o futuro. 5. ed. São Paulo : Perspectiva, 1978. p. 249-280. (Debates. Política, 64).

ARENDT, H. Condition de I'homme moderne. Paris: Calman-Lévy, 1983.

BETTELHEIM, B. A psicanálise dos contos de fadas. Rio de Janeiro: Paz e Terra, 1980.

BOURDIEU, P. Le sens pratique. Paris: Minuit, 1980.

BRUNER, J. Atos de significação. Porto Alegre: Artes Médicas, 1997.

CASTELLS, M. A sociedade em rede. 3.ed. São Paulo: Paz e Terra, 1999. (A era da informação: economia, sociedade e cultura, 1).

CAUNE, J. La médiation culturelle: une construction du lien social. 1999a.

Disponível em: <http://lesenjeux.u-grenoble3.fr/2000/Caune/index.php>. Acesso em: 25 jul 2010.

CAUNE, Jean. Pour une éthique de la mediation: le sens des pratiques culturelles. Grenoble : Presses Universitaires de Grenoble, 1999b. 
DARRAS, B. Étude des conceptions de la culture et de la médiation. MEI « Médiation et information », Paris, n.19, 2003. Disponível em: <http://www.meiinfo.com/wp-content/uploads/revue19/ilovepdf.com_split_4.pdf>. Acesso em: 24 abr. 2010.

DAVALLON, J. La médiation: la communication en procès? Médiations \& Médiateurs, n. 19, fev. 2004. Disponível em: <http://revistas.ua.pt/index.php/prismacom/article/viewFile/645/pdf>. Acesso em: 18 jul. 2011

DUFRÊNE, B. GELLEREAU, M. La médiation culturelle: métaphore ou concept ? Propositions de repères. In: CONGRÈS NATIONAL DES SCIENCES DE L'INFORMATION ET DE LA COMMUNICATION, 12, 2001. Paris. Actes... Paris : Unesco, 2001. p. 233-240.

DUFRÊNE, B; GELLEREAU, M. La médiation culturelle: enjeux professionels et politiques. Hermès, n. 38: p. 199-206, 2004.

ESCARPIT, R. L'écrit et la communication. Paris: PUF, 1974.

GOODY, J. Pouvoirs et savoirs de l'écrit. Paris: La Dispute/SNEDIT, 2007.

JEANNERET, Y. Médiation. In: La societé de l'information: glossaire critique. Paris: La Documentation Française, 2005. p. 105-107. Disponível em: <http://www.diplomatie.gouv.fr/fr/IMG/pdf/Glossaire_Critique.pdf>. Acesso em 20 jan. 2014

La FORTUNE, J-M. La médiation culturelle: le sens des mots et l'essence des pratiques. Québec: Presse de I'Université du Québec, 2012.

LALANDE, André. Vocabulário técnico e crítico da Filosofia. São Paulo: Martins Fontes, 1993.

LAMIZET, B. La médiation culturelle. Paris: L'Harmattan, 2000.

Le DEUFF, O. La culture de l'information en reformation. Rennes, 2009. Thèse (Doctorat) - Université de Rennes, 2. Disponível em: <http://tel.archivesouvertes.fr/docs/00/42/19/28/PDF/theseLeDeuff.pdf>. Ácesso em: 30 jul. 2012

LISPECTOR, C. Felicidade Clandestina: contos. Rio de Janeiro: Nova Fronteira, 1981.

MARTIN-BARBERO, J. De los medios a las mediaciones: comunicacion, cultura y hegemonia. 2. ed. Barcelona: Gustavo Gili, 1991.

MORIN, E. Introdução ao pensamento complexo. Porto Alegre: Sulina, 2005.

PERAYA, D. Médiation et médiatisation: le campus virtuel. Hermès, n. 25, p.199206, 1999. Disponível em: <http://hdl.handle.net/2042/14983<. Acesso em: 21 jun. 2010. 
PERROTTI, E.; PIERUCCINI, I. Infoeducação : saberes e fazeres da contemporaneidade. In: LARA, M. L. G, FUJINO, A. NORONHA, D. P. (Orgs.). Informação e contemporaneidade: perspectivas. Recife: Néctar, 2008. p. 46-97.

PLATÃO. Fedro. São Paulo: Martin Claret, 2002.

PRIGOGINE, I. O fim das certezas: tempo, caos e as leis da natureza. São Paulo: Unesp, 1996.

VYGOTSKY, L.S. A formação social da mente. São Paulo: Martins Fontes, 1991. WINNICOTT, D. W. O brincar e a realidade. Rio De Janeiro: Imago, 1975.

\section{Title}

The cultural mediation as an autonomous category

\section{Abstract}

Introduction: Reflections on the notion of cultural mediation, as a theoretical and operational autonomous category, defined through continuous liaison with the production and reception of cultural, considered dynamic and complex processes governing the symbolic ecology.

Objective: To define cultural mediation as essential instance of the production processes of meaning

Methodology: the study of the components of an autobiographical cultural experience, reported by Clarice Lispector in the tale named Happiness Clandestine.

Results: cultural mediation is not simple resource to transfer data / information, mere "channel" or agency of support aimed at creating links between people.

Conclusion: The cultural mediation is an autonomous act, with its own identity and logic, defined in relation to the spheres of production and reception of information and culture. Such an approach, assuming triadic model (mediation-production-reception), breaks with dualistic and mechanical insights from the fields of Information and Communication, being heuristic, since it is compatible with the centrality of cultural mediation arrangements today.

Key words: Cultural mediation. Cultural paradigms. Cultural appropriation.

\section{Título}

La mediación cultural como una categoría autónoma

\section{Resumen}

Introducción: reflexiones sobre la noción de mediación cultural, como categoría autónoma teórica y operativa, que se define a través de un enlace permanente con las categorias da producción y recepción culturales, proprios de los procesos dinámicos y complejos, que rigen la ecología simbólica. 
Objetivo: Definir la mediación cultural como instancia esencial de los procesos de producción de significado

Metodología: el estudio de los componentes de una experiencia cultural autobiográfica, reportada por Clarice Lispector en el cuento Felicidad Clandestina.

Resultados: la mediación cultural no es simple recurso de transferencia de datos / información, mero "canal" o instancia de apoyo dirigido a la creación de vínculos entre los sujetos.

Conclusión: El acto de mediación cultural es autónomo, con su propia identidad y lógica, que se define en relación con las esferas de la producción y la recepción de la información y la cultura. Tal enfoque, asumiendo modelo triádico (mediación-producción-recepción), rompe con ideas dualistas y mecánicas de los campos de la Información y la Comunicación, siendo heurística, ya que es compatible con la centralidad de los dispositivos de mediación cultural de hoy.

Palabras clave: Mediación cultural. Paradigmas culturales. Apropiación cultural.

Recebido em: 15.07.2014

Aceito em: 05.10.2014 